\title{
Well-being in Europe: Decompositions by country and gender for the population aged $50+$
}

\author{
Claudia Reiter ${ }^{1}$ and Sonja Spitzer ${ }^{1,2, *}$
}

\begin{abstract}
The well-being of older Europeans is of increasing importance given the substantial ageing of the population. This paper comprehensively analyses well-being for the population aged $50+$ in 26 European countries, using the newly proposed indicator "Years of Good Life" (YoGL), which measures the remaining years of life that an individual can expect to live in a "good" state. The indicator enables the decomposition of well-being into various dimensions, thereby revealing important heterogeneities between regions and genders. Results show that numbers of YoGL at age 50 vary considerably between European countries. They are highest in Northern and Western European countries and lowest in Central and Eastern European countries, where many "good" years are lost due to low life satisfaction. Interestingly, the high life expectancy levels in Southern Europe do not translate into higher numbers of YoGL, mainly due to the low levels of physical and cognitive health in this region. While women and men can expect to have similar numbers of YoGL, women are likely to spend a smaller proportion of their longer remaining lifetime in a good state. These results demonstrate the importance of using wellbeing indicators that consider population heterogeneity when measuring human well-being, especially for older populations.
\end{abstract}

Keywords: well-being; population 50+; Europe; SHARE data; Sullivan's method, cross-country analysis

\footnotetext{
${ }^{1}$ Department of Demography, University of Vienna, Wittgenstein Centre for Demography and Global Human Capital (IIASA, OeAW, University of Vienna), Vienna, Austria

${ }^{2}$ The authors are listed in alphabetical order with equal contributions.

*Correspondence to: Sonja Spitzer, sonja.spitzer@univie.ac.at
} 


\section{Introduction}

Longevity is one of the biggest achievements of modern societies. In the past 20 years, the European population has, on average, gained more than five years of life expectancy. Consequently, old- and middle-aged people represent an everincreasing proportion of the population in Europe, a trend that is further exacerbated by declining fertility rates and reinforcing migration patterns in some countries. In 2019, 39.6\% of all Europeans were aged 50 or older (United Nations 2019). This share is expected to further increase: according to projections by the Wittgenstein Centre for Demography and Global Human Capital (2018), the majority of the European population will be aged $50+$ by the end of the century.

In the light of these developments, gaining a deeper understanding of well-being in older age groups, as well as of the main factors that influence it, is not only interesting for researchers, but is highly relevant for policy-makers, and for society as a whole. Although the number of studies that seek to measure and quantify quality of life has been increasing, there is little existing research that has focused on the various aspects of well-being in older age groups. In particular, few studies have examined well-being from a more comprehensive perspective by going beyond a sole focus on the health-related aspects of quality of life. In this paper, we analyse comprehensive well-being based on a newly proposed indicator called "Years of Good Life" (YoGL), which considers mortality and physical and cognitive health, but also other aspects of quality of life, including poverty and subjective well-being. Furthermore, we contribute to the literature by decomposing well-being into various dimensions, thereby revealing old-age-specific country and gender differences in well-being for 26 European countries.

The remainder of the paper is structured as follows. Section 2 outlines the conceptual approach, and relates it to previous literature. Section 3 describes the data utilised, and Section 4 introduces the methods employed. Results and robustness analyses are presented and discussed in Section 5. Section 6 concludes and discusses potential limitations.

\section{Conceptualisation and related work}

In this paper, we make use of the novel comprehensive well-being indicator YoGL, a measure developed by Lutz et al. (2021), which aims at estimating the remaining years of life an individual can expect to live in a "good" state. By focusing on the changing composition of human populations with regard to the characteristics that reflect a society's aggregate level of human well-being, the indicator is tailor-made to serve as an outcome that can be used to judge the sustainability of long-term development trajectories (Matson et al. 2016).

The measure is based on the assumption that in order to be able to enjoy any quality of life, a person has to be alive. However, since mere survival does not sufficiently capture well-being, "years of good life" are made conditional on meeting minimum 
Figure 1:

Dimensions of Years of Good Life

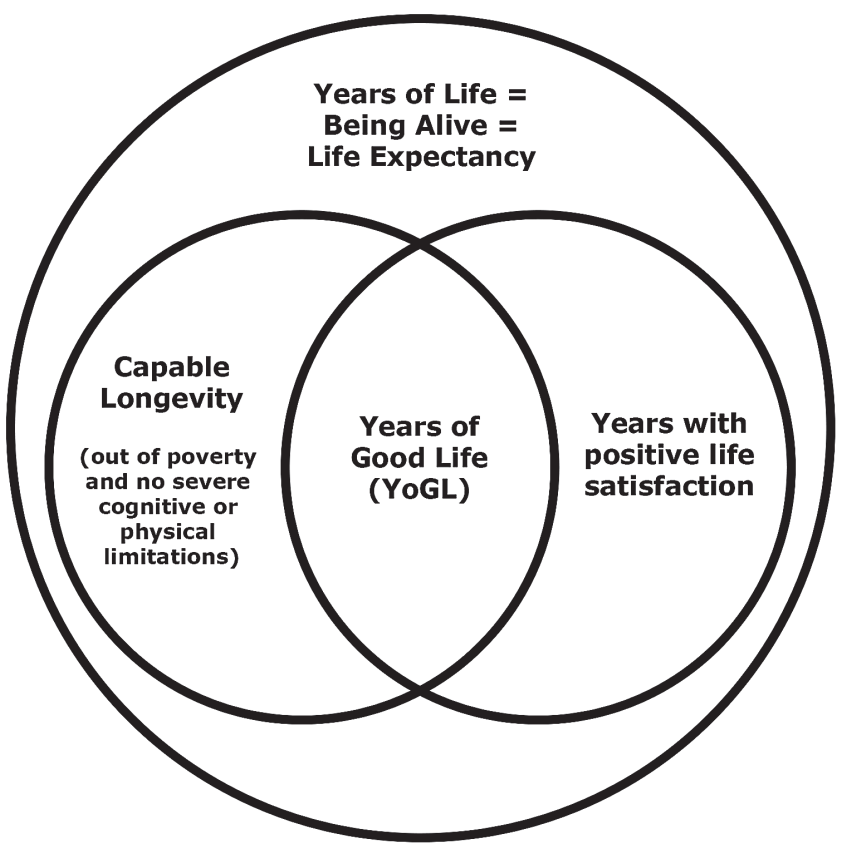

Note: Based on Lutz et al. (2021).

standards of objectively observable conditions (capable longevity), as well as of subjective life satisfaction. Building on earlier works of Sen (Desai et al. 1992), the objective conditions measuring "capable longevity" are further broken down into three separate dimensions: being out of poverty, being cognitively enabled, and having no serious physical disabilities. Only if people are above critical levels in all three objective dimensions and in their self-reported overall life satisfaction are the life years considered as "good" years in the calculation of YoGL. Figure 1 summarises this structure and the basic logic of the YoGL indicator, demonstrating that it represents the intersection of capable longevity and years with positive life satisfaction as a subset of overall years of life. ${ }^{1}$

Our analysis focuses on the expected years of good life at age 50 for men and women in 26 European countries. As people age, their physical and mental capabilities decline, even as their levels of financial dependence and social isolation

\footnotetext{
1 More detailed information about the theoretical foundations of the indicator, as well as a comparison between YoGL and other existing well-being indicators, can be found in Lutz et al. (2021) and Reiter and Lutz (2020).
} 
increase. Thus, the elderly are particularly vulnerable to experiencing limitations in their capable longevity and deterioration in their life satisfaction (Netuveli and Blane 2008). While we acknowledge that most 50-year-olds are still in their prime of life, are active on the labour market, and are in good health, the methodology of YoGL allows us to not only capture age-specific well-being at age 50, but to take into account expected well-being in later years of life (for a more detailed description of the methodology and calculation of YoGL, see Section 4.1).

The previous studies that analysed the well-being of older adults often had a strong focus on health dimensions; i.e., they used summary measures for population health as measures of well-being. Prominent examples of these indicators include Quality Adjusted Life Expectancy (Zeckhauser and Shepard 1976), Disability Adjusted Life Expectancy (Murray and Lopez 1994), and Healthy Life Years (Robine 2006) - all of which were calculated by combining life table information with information on the prevalence of health states or diseases. Analyses based on these indicators have found considerable heterogeneities in health-related wellbeing between European countries, as well as between sub-populations by age and gender (Heijink et al. 2011; Jagger et al. 2008).

Overall, we expect the prevalence of the objective dimensions of YoGL - i.e., capable longevity - to decrease with rising age. Individual ageing leads to a gradual decrease in physical and mental capacity and a growing risk of disease (World Health Organization 2018). Thus, as a population ages, a smaller proportion of the total population is cognitively enabled and free of serious physical disabilities. In addition, for older people, particularly for older women, the risk of poverty increases with age (Eurostat 2020c). However, in many highly developed European countries, extensive welfare systems and efficient redistribution measures ensure that the actual proportion of the population living below the poverty line is kept to a minimum, including among the elderly population.

The relationship between ageing and subjective life satisfaction is more ambiguous, with previous research suggesting that average levels of life satisfaction may decrease, increase, or remain relatively constant across the lifespan (Horley and Lavery 1995; Lelkes 2008; Steptoe et al. 2015). For example, in a study on self-assessed life satisfaction among the elderly population in Sweden, Austria and Germany, Kutubaeva (2019) found no evidence that ageing itself necessarily worsens an individual's perception of life. By contrast, Angelini et al. (2012) came to the conclusion that age influences life satisfaction among Europeans through two counterbalancing channels: i.e., on the one hand, increasing age leads to an increase in the perceived level of life satisfaction; and, on the other, it results in a shift in the individual thresholds that determine whether an individual is satisfied with her life. Nevertheless, although there are inconsistencies in the previous research findings, a certain impact of old-age-specific burdens (e.g., dependency or reduced social contact through isolation or the deaths of friends and family) on life satisfaction cannot be ruled out.

The indicator YoGL is designed in such a way that it does not apply a standard weighting structure to its constituents or rely on implicitly assumed trade-offs 
(Lutz et al. 2021; Reiter and Lutz 2020). Therefore, a high level of life satisfaction does not, for example, counterbalance severe physical limitations. On the contrary, when an individual's life satisfaction is low solely because of her strong functional limitations, "double-counting" is also avoided by design. While we appreciate that YoGL is a substantively justified combined measure, we also want to highlight the usefulness of decomposing the indicator into its four dimensions (see Section 4.2). This is especially relevant when analysing older age groups, as the challenges posed by population ageing at various levels of society are crucial concerns for policymakers. By gaining a better understanding of why a population is losing good years of life, sustainable prevention strategies can be formulated to help individuals preserve their well-being in old age.

\section{Data}

The analysis is based on two different data sources. Individual-level information on the objective and subjective dimensions of YoGL is based on the Survey of Health, Ageing and Retirement in Europe (SHARE). Additional aggregated data for the model-based out-of-sample predictions of physical health, as well as countryspecific life tables, are taken from Eurostat.

\subsection{Survey of Health, Ageing and Retirement in Europe}

We analyse YoGL for Europe based on SHARE, a multidisciplinary cross-country survey providing micro-level information on the health, well-being and socioeconomic characteristics of around 140,000 individuals, based on data collected in around 380,000 interviews (Börsch-Supan et al. 2013). These survey data are especially well-suited for analysing YoGL in European countries: first, because the data are ex-ante harmonised; and, second, because the data include information on all four dimensions needed to compute the indicator. The survey's target population consists of all non-institutionalised individuals aged 50 and older. This analysis is based on the most recent Wave 7 from 2017, which includes European countries as well as Israel (Bergmann et al. 2019; Börsch-Supan 2019b). We keep all European individuals, which results in 70,191 observations from 26 countries: namely, Austria, Belgium, Bulgaria, Croatia, Cyprus, Czechia, Denmark, Estonia, Finland, France, Germany, Greece, Hungary, Italy, Latvia, Lithuania, Luxembourg, Malta, Poland, Portugal, Romania, Slovakia, Slovenia, Spain, Sweden and Switzerland. In addition, information from Wave 5 (2013) is utilised for out-of-sample predictions of physical health (Börsch-Supan 2019a; Malter and Börsch-Supan 2015). Wave 5 includes only 14 European countries: namely, Austria, Belgium, Czechia, Denmark, Estonia, France, Germany, Italy, Luxembourg, Netherlands, Slovenia, Spain, Sweden and Switzerland. In total, they provide 59,713 observations. 
Before describing in detail the operationalisation of the different YoGL dimensions, we should stress that the concept of the indicator is based on one specific interpretation of human well-being that focuses on longevity combined with being above minimum thresholds in further dimensions of well-being. This focus on basic material needs, basic physical and mental functioning, and having at least a medium level of life satisfaction is highly sensitive to improvements at the tail end of the population distribution, but is insensitive to improvements in the upper parts. Our decision to focus on the tail end rather than the mean of the distribution is in line with the "leave no-one behind" principle, which is also promoted in the Sustainable Development Goals (UN System Chief Executives Board for Coordination 2017).

\subsubsection{Objective YoGL dimensions}

Being out of poverty. Following Lutz et al. (2021), individuals are considered poor if their income falls below the World Bank poverty line for upper-middle income countries of US\$5.50 PPP per day (Ferreira and Sánchez-Páramo 2017). More specifically, poverty is assessed based on an individual's total monthly household income after taxes and contributions. Income is equivalised by employing the square root scale that is also used in OECD (2011) and OECD (2008), in which household income is divided by the square root of the household size. It is then adjusted for differences in purchasing power and converted to international dollars per day. Table 1 displays the shares of men and women who are out of poverty in each country. It shows that in Europe, most individuals aged 50 and older are above the World Bank poverty line, except in poor countries such as Bulgaria, Latvia and Romania. Table 2 provides summary statistics for income, as well as for all of the other variables utilised.

Without cognitive limitations. Cognitive limitations are measured via a memory performance test. At the beginning of the test, the interviewer reads aloud a list of 10 words. The participants are then asked to repeat as many of these words as possible within one minute. On average, individuals recall 5.2 words. Memory scores are highest in Switzerland (6.0 words) and lowest in Portugal (3.9 words), which is also the only country in which no participant recalled more than eight words. As suggested in the previous literature, participants are considered cognitively impaired if they recall only three words or less (Grodstein et al. 2001; Purser et al. 2005; Spitzer and Weber 2019). For robustness analyses, the threshold is set at two words or less (Section 5.3). Again, descriptive results and summary statistics are provided in Tables 1 and 2.

Without physical limitations. Finally, physical limitations are assessed via a chair stand performance test. The test is introduced by the interviewer saying: "The next test measures the strength and endurance in your legs. I would like you to fold your arms across your chest and sit so that your feet are on the floor; then stand up keeping your arms folded across your chest. Like this..." The survey participants are asked if they think it would be safe to try to stand up from a chair, and the 


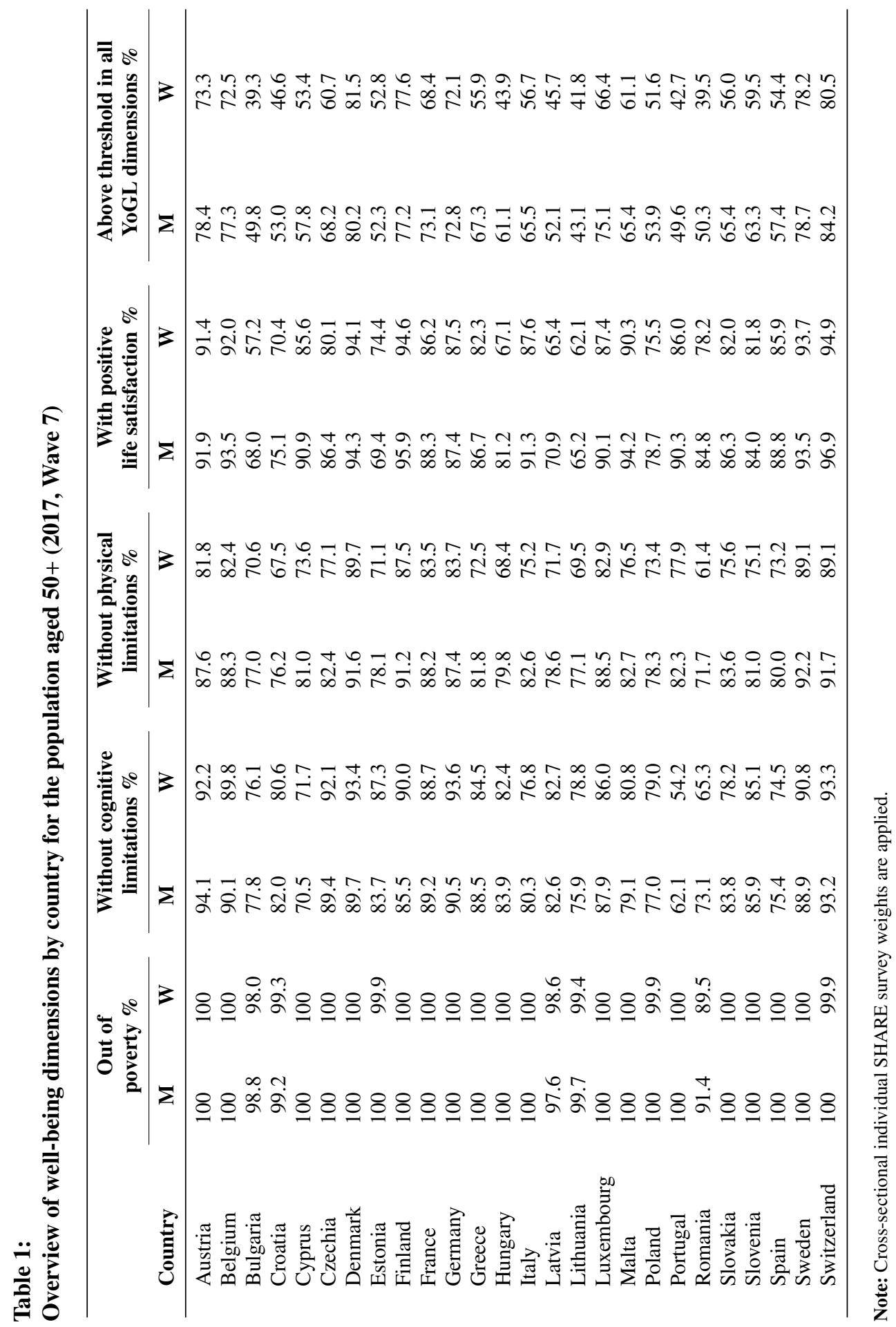


Table 2:

Summary statistics (2017, Wave 7)

\begin{tabular}{lccccc}
\hline & $\boldsymbol{N}$ & Mean & SD & Min. & Max. \\
\hline Age (in number of years) & 69,897 & 66.61 & 10.156 & 51 & 105 \\
Gender (1 = woman) & 69,897 & 0.54 & 0.498 & 0 & 1 \\
$\quad$ Yearly equivalised household & 69,400 & 18,408 & 14,565 & 428 & 417,137 \\
$\quad$ income (in Intl\$) & & & & & \\
$\quad \begin{array}{l}\text { Number of words recalled } \\
\text { Predicted ability to stand }\end{array}$ & 69,181 & 5.19 & 1.812 & 0 & 10 \\
$\quad$ up from a chair & 65,450 & 0.81 & 0.218 & 0 & 1 \\
$\quad$ Life satisfaction & 69,897 & 7.56 & 1.818 & 0 & 10 \\
\hline
\end{tabular}

Note: Cross-sectional individual SHARE survey weights are applied.

test is conducted only if they agree. Following Lutz et al. (2021), individuals are considered to be free from physical limitations if they are able to stand up from the chair without using their arms. By contrast, participants are considered to be physically impaired if they are unable to stand up from the chair, if they have to use their arms to stand up from the chair, or if they think that it is unsafe to participate in the test in the first place. Previous literature has shown that the share of participants who are categorised as physically impaired hardly changes when individuals who use their arms to stand up are considered to be unimpaired (Spitzer and Weber 2019).

The chair stand test was conducted in Wave 2 (2006-2007) and in Wave 5 (2013), but not in Wave 7 (2017). Hence, we use information from Wave 5, the most recent wave in which the chair stand test was administered, to extrapolate data to Wave 7. Details on the methods and robustness analyses are provided in Sections 4.3 and 5.3. Based on these out-of-sample predictions, $81 \%$ of the participants are considered to be without physical limitations. Descriptive results and summary statistics are again provided in Tables 1 and 2, along with information for the robustness analyses in the Appendix.

\subsubsection{Subjective dimension}

Subjective well-being is assessed via a standard 10-step Likert-scale based on the question: "On a scale from 0 to 10 where 0 means completely dissatisfied and 10 means completely satisfied, how satisfied are you with your life?" On average over all of the countries in the sample, individuals reported a value of 7.6 (Table 2). Individuals are considered to be satisfied if they reported a value larger than five. For robustness analyses, a cut-off of four is also considered (Section 5.3).

After assessing the objective and subjective dimensions, we add a binary code to each observation that indicates whether the individual is above the critical threshold 
in all four YoGL dimensions. Finally, country-specific proportions by 10 -year age groups $^{2}$ and gender are aggregated using calibrated cross-sectional survey weights, as provided by SHARE. We find that, on average across all of the countries in the sample, $63.6 \%$ of individuals are simultaneously out of poverty, report positive life satisfaction, have basic cognitive abilities, and have no severe activity limitations. Simple correlation matrices for all dimensions per country and gender are provided in Table A.1 in the Appendix.

\subsection{Eurostat}

\subsubsection{Eurostat data on health expenditure}

For the model-based out-of-sample predictions (see Section 4.3), country-level information on health expenditures is utilised. These data are provided by Eurostat (2020a). In particular, we utilise total general government expenditure on health as a percentage of GDP in the respective year; i.e., 2013 for Wave 5 and 2017 for Wave 7.

\subsubsection{Eurostat life tables}

Gender-specific period life tables for the year 2017 for all 26 countries in our sample also come from Eurostat (2020b). As these life tables are reported by single-year age groups, standard life table techniques were applied to transform them into abridged life tables with 10-year age intervals.

\section{Method}

\subsection{Sullivan method}

The calculation of YoGL is based on demographic life table methods (Sullivan method) in which age-specific person-years lived at each age are multiplied by agespecific proportions considered to be above the critical threshold in all four YoGL dimensions (Sullivan 1971). Consequently, a year is only counted as a good year for those individuals who are above the critical thresholds in all four dimensions; and

\footnotetext{
2 Using five-year age groups would reduce the number of countries for which we can estimate the remaining years of good life at age 50, since SHARE data do not include observations of men and women for the age group 50-54 for Hungary, Portugal and Sweden. Instead, 10-year age groups are used to calculate prevalence rates and life tables. This has the additional benefit of increasing the number of observations for each age group. Sensitivity analyses revealed that the results hardly differ depending on whether five-year age groups or 10-year age groups are used.
} 
no trade-offs or compensatory mechanisms are assumed between the dimensions. Summing up the age-specific person-years of good life for all of the remaining age groups above the age at which remaining life expectancy will be assessed results in the expected total years of good life. Formally, the calculation can be summarised in the following mathematical notation:

$$
\frac{1}{l_{x}} \sum_{i=x}^{A} \pi_{i} L_{i}
$$

where $l_{x}$ denotes the number of survivors at age $x_{i}$ (beginning of the interval $i$ ); $L_{i}$ indicates the number of person-years lived in the age group $i$; and $\pi_{i}$ denotes the prevalence of the state of interest, i.e., country-specific proportions of the population above a critical level in all four dimensions by 10-year age groups and gender.

As with total life expectancy, YoGL can be assessed at birth, as well as at any other age considered appropriate. As the focus of this paper is, however, on the well-being of older adults, we calculate YoGL at age 50.

\subsection{Decomposition}

By decomposing YoGL into four different dimensions, we are able to better understand why a population is losing good years of life. The methodology we apply here resembles the calculation of YoGL using the Sullivan method; however, in this case, the prevalence of the state of interest is decomposed into four different proportions: proportion of the population who are out of poverty $\left(\pi_{i}^{p}\right)$, proportion of the population with basic cognitive ability $\left(\pi_{i}^{c}\right)$, proportion of the population without severe activity limitations $\left(\pi_{i}^{h}\right)$ and proportion of the population with positive life satisfaction $\left(\pi_{i}{ }^{S}\right)$.

This approach enables us to calculate four sub-indicators, which we call "years of life out of poverty", "years of life without severe activity limitations", "years of life with basic cognitive ability" and "years of life with positive life satisfaction". Given that the YoGL indicator is based on no implicit trade-off assumptions or weighting structures, it must hold that the number of years of good life is less than or equal to each of the four sub-indicators for every (sub-)population.

\subsection{Model-based out-of-sample predictions}

The YoGL calculations are based on data from Wave 7, because it is the most recent wave, and includes more countries than any previous SHARE survey wave. Wave 7 does not, however, include information on the performance-tested ability to stand up from a chair. Thus, the data are extrapolated from Wave 5, which is the most recent SHARE wave in which the chair stand test was conducted. For the out-of-sample predictions, the information on the ability to stand up from a chair 
from Wave 5 (2013) is regressed on crucial determinants on both the individual and the country level. These determinants include demographic and socio-economic characteristics, information on physical and cognitive health (most importantly, the self-reported ability to stand up from a chair), country-level health expenditure, region dummies, as well as the other three well-being dimensions (being out of poverty, having positive life satisfaction and basic cognitive ability). Using the same determinants from Wave 7 (2017) enables us to predict levels of physical health for 2017. A detailed list of variables along with summary statistics is provided in Table A.2 in the Appendix.

Since the outcome variable is binary, a logistic regression model is utilised for the regression. Standard errors are clustered at the household level. The output table is provided in the Appendix (Table A.3). Overall, the non-linear extrapolation model yields a relatively high Pseudo $\mathrm{R}^{2}$ of 0.27 . The model fits the underlying data well, as shown in Figure A.1 in the Appendix. In all of the countries that participated in Wave 5, the share of individuals with physical limitations based on the predicted data is virtually identical to the share based on the observed data. Exceptions include Czechia, Luxembourg, Austria and Spain; but even in those countries, the difference never exceeds four percentage points. Nevertheless, we conduct robustness analyses in which we compare YoGL based on predicted physical limitations with YoGL based on observed physical limitations for Wave 5 (Section 5.3).

\section{Results}

\subsection{Country and gender differences}

Figure 2 displays YoGL at age 50 by country and gender. It also shows life expectancy at age 50, and ranks countries accordingly, which allows us to analyse the relationship between remaining years of life and remaining years of good life. On average, the YoGL at age 50 are 19.7 years for women and 18.6 years for men. The results also show, however, that the numbers of YoGL vary considerably between countries. In 2017, 50-year-old Swiss women can expect to live another 36.6 years, of which 28.7 are considered good years. Hence, these women can expect to spend $78.4 \%$ of their remaining lifetime as good years. By contrast, 50year-old Bulgarian women have a life expectancy of 30.4 additional years in 2017, of which just 12.1 years are considered good years, resulting in a proportion of only $39.8 \%$. The findings for men are very similar. The projected numbers of YoGL for men are highest in Switzerland (27.2 years) and are lowest in Lithuania (10.6 years) and Bulgaria (12.5 years).

Overall, life expectancy at age 50 is highest in Southern Europe and Switzerland, followed by Northern and other Western European countries. For example, 50-yearold women in Spain can expect to live another 37.1 years, and 50-year-old men in Switzerland can expect to live another 33.1 years. The high life expectancy in 
Figure 2:

Remaining Years of Good Life at age 50 by country and gender (2017, Wave 7)

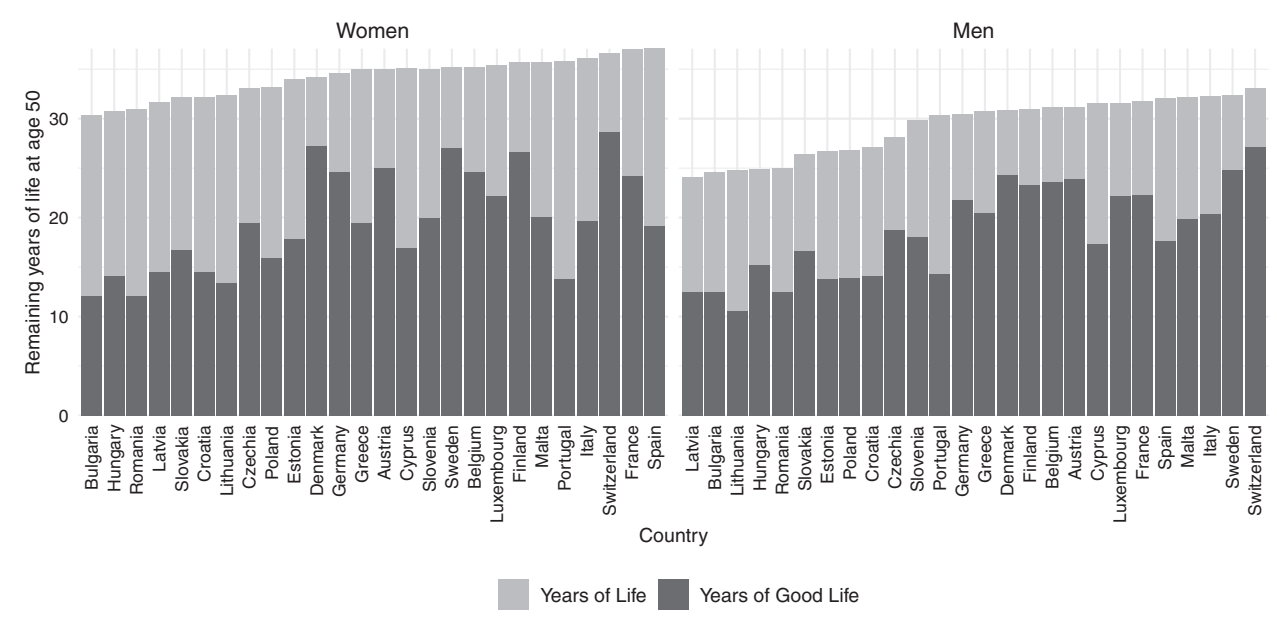

Note: Cross-sectional individual SHARE survey weights are applied.

Southern Europe does not, however, translate into more YoGL. Indeed, despite its relatively high life expectancy, especially for women, Portugal is among the countries with the lowest numbers of YoGL. Instead, the Northern and Western European countries are the leaders in YoGL for both men and women. The highest numbers of YoGL are observed in Switzerland and in Northern European countries such as Sweden and Denmark, followed by in other Western European countries. Consequently, these are also the countries with the highest proportions of remaining years of good life compared to the total remaining years of life. However, Central and Eastern European countries have both low life expectancy and lower numbers of YoGL. These differences between overall life expectancy and YoGL confirm the importance of differentiating between mere survival and well-being.

Figure 3 shows the gender differences in YoGL and life expectancy at age 50 by country. In general, women have higher life expectancy than men. While this pattern holds for all countries, the gender gap in life expectancy is largest in Latvia (7.6 years) and Lithuania (7.5 years), and is smallest in Sweden (2.7 years). On average over all of the countries in our sample, women's life expectancy exceeds men's life expectancy by 4.9 years. Interestingly, however, the differences in YoGL are very small. On average, the gap in YoGL between women and men is only 1.1 years. This suggests that women's advantage in life expectancy does not translate into an equal advantage in good years. The only exceptions to this general pattern are Denmark and Sweden, where the gender gap in YoGL is only slightly smaller than the gender gap in life expectancy. In seven countries (Hungary, Greece, Italy, 
Figure 3:

Gender differences in Years of Good Life and life expectancy at age 50 by country (2017, Wave 7)

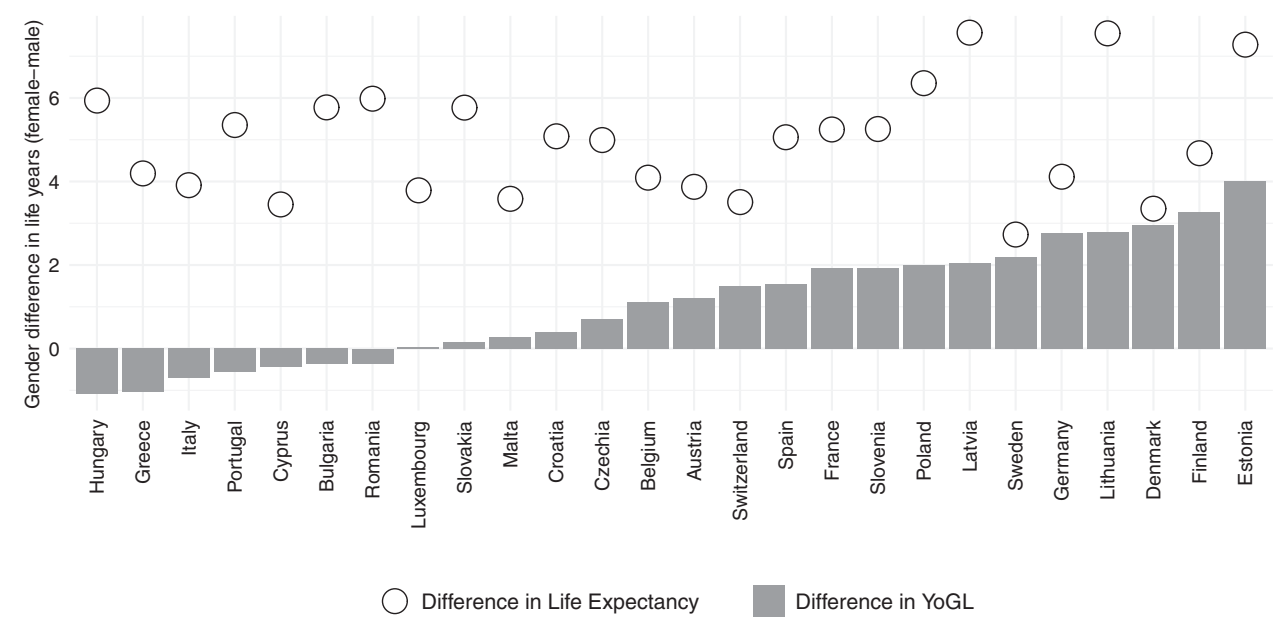

Note: Cross-sectional individual SHARE survey weights are applied.

Portugal, Cyprus, Bulgaria and Romania), the numbers of YoGL at age 50 are even lower for women than for men.

As a result of the gender disparities noted above, women have, on average, a much lower proportion of remaining years of good life than of remaining years of life. While men at age 50 can expect, on average, to spend $62.7 \%$ of their remaining time as good years, the corresponding share for women is just $57.1 \%$. The proportions of remaining years of good life are particularly low for women in Portugal (38.6\%), Romania (39.1\%) and Bulgaria (39.8\%). These results are related to the "malefemale health-mortality paradox" (di Lego et al. 2020), a term that is used to refer to the phenomenon that, on average, women live longer than men, but spend a larger proportion of their life in poorer health (Luy and Minagawa 2014; Pongiglione et al. 2015).

\subsection{Decomposition}

Decomposing YoGL into four dimensions allows us to better understand why countries are losing good years of life. The results presented in Figures 4 and 5 clearly show that, overall, most good years are lost due to limitations in physical health, followed by limitations in cognitive health. By contrast, poverty has only small effects on YoGL, since most Europeans are considered to be out of poverty according to the definitions described above. The countries with the lowest numbers 

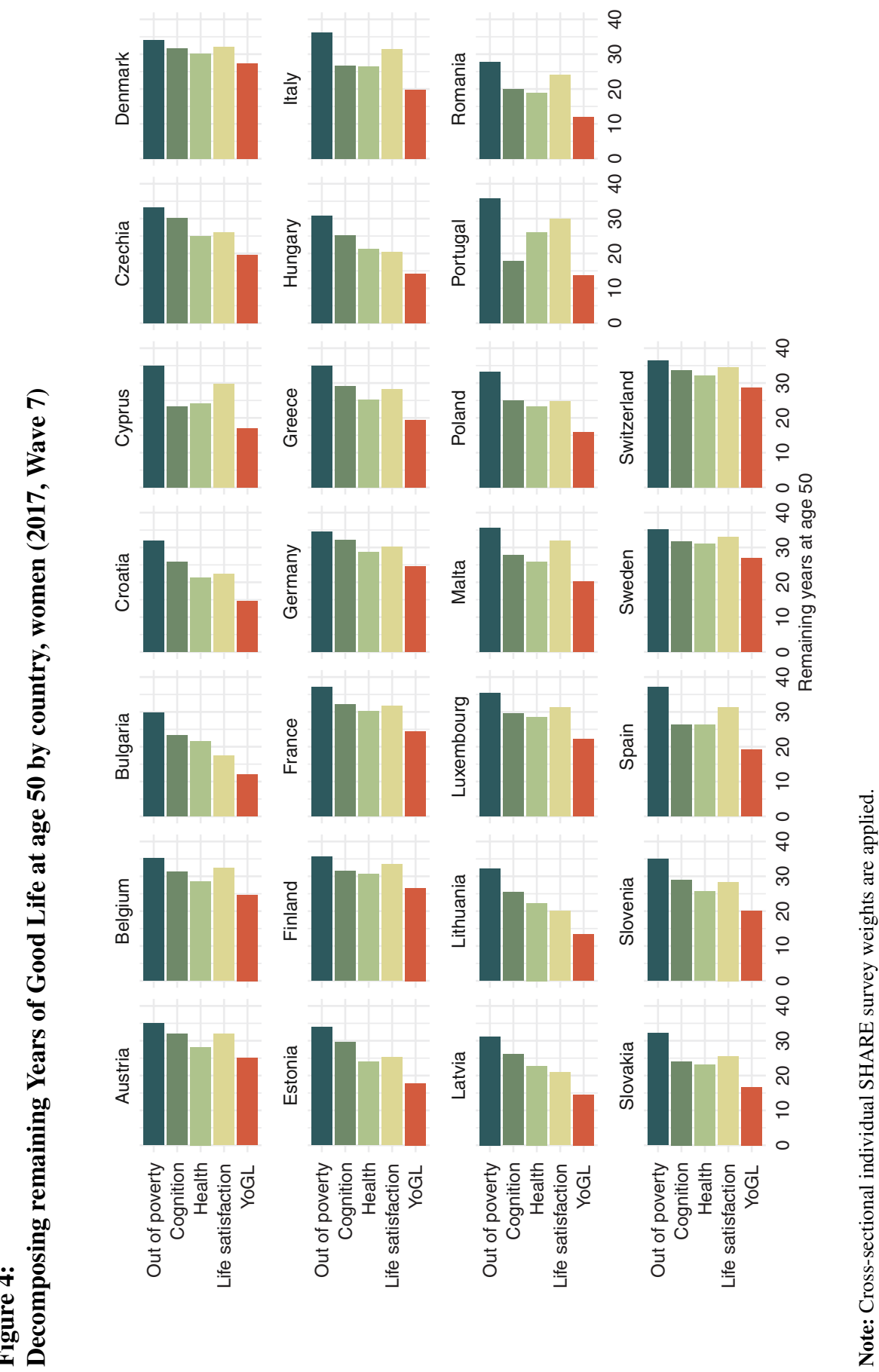

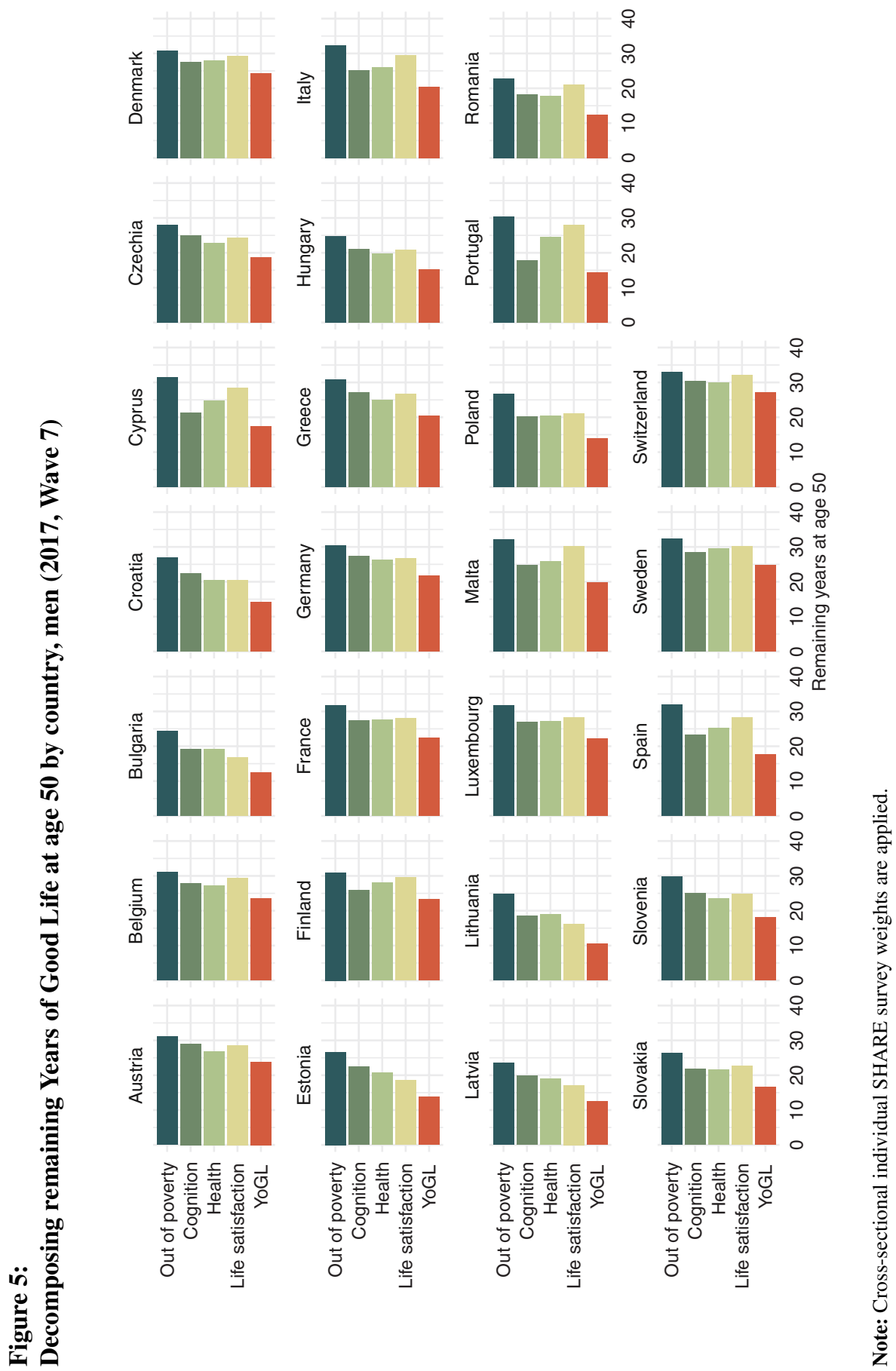
of years of life out of poverty are all Central and Eastern European countries; but even in those countries, more YoGL are lost due to deductions in the other dimensions. Related literature has, however, suggested that poverty plays an important role in the lower levels of well-being observed in low-income countries outside of Europe, and in trends in YoGL over time (Reiter and Lutz 2020; United Nations Development Programme 2019).

Analysing the decomposition separately by country and gender reveals that there are big differences in the composition of YoGL. While the reduction in good years due to low life satisfaction plays a small role in most countries, it is highly relevant for Central and Eastern European countries. In Bulgaria, Hungary, Lithuania and Latvia, it is even the main reason for the reduction in good years; thus, in these countries, life satisfaction has a bigger impact on YoGL than physical and cognitive health. These results are very much in line with previous findings showing that in Central and Eastern European countries, life satisfaction is persistently low (Dingemans and Henkens 2018; Guriev and Zhuravskaya 2009). This pattern has often been attributed to the impact of the post-communist transition and the related increases in inequality and uncertainty (Djankov et al. 2016; Sanfey and Teksoz 2007).

Women lose most of their YoGL due to their physical limitations. Among men, however, the negative effects of physical and cognitive limitations are almost identical. These results have to be interpreted against the backdrop of differences in overall life expectancy. As we mentioned above, women spend a larger proportion of their overall lifetime in poor health. Similar results are found for life satisfaction. While women spend more years with positive life satisfaction than men, they spend a smaller proportion of their lifetime with positive life satisfaction than men.

\subsection{Robustness analyses}

Sensitivity analyses displayed in Table A.4 and Figures A.2, A.3 and A.4 in the Appendix show that the results discussed above are robust. As we discussed in Section 3.1, we consider different thresholds for physical limitations, cognitive limitations and subjective well-being. Furthermore, we compare YoGL based on predicted and observed physical limitations for countries that participated in Wave 5.

The results of the main analysis show that $63.6 \%$ of the population are simultaneously out of poverty, report positive life satisfaction, have basic cognitive ability and suffer from no severe activity limitations. This share hardly changes when the robustness analyses are applied. Decreasing the threshold for cognitive limitations to two words instead of three words increases the share of individuals who are above the threshold in all YoGL dimensions to $68.6 \%$; while decreasing the threshold for positive life satisfaction from five to four increases the share to $68.7 \%$.

As can be seen in Figure A.2, changing the threshold for cognitive limitations leaves the results virtually unchanged for most countries. Although YoGL increase slightly when the more lenient threshold is applied, the country ranking and related 
results are hardly affected. One exception is Portugal, where YoGL increases substantially based on the new threshold, especially for men. The reason for this increase is that cognitive ability in Portugal has a different distribution than it does in the other countries. First, as mentioned above, Portugal is the only country in which no participant remembered more than eight words - in all other countries, the maximum is 10 words. Second, while the number of words recalled is normally distributed in most countries, the Portuguese distribution has an additional concentration around three words. Hence, whether the threshold is set at two or three words makes a greater difference for Portugal than it does for the other countries. When we look at the distribution of the number of words in previous waves in Portugal, this curious distribution does not appear. Thus, we conclude that the results for Portugal need to be treated with caution.

Decreasing the threshold for positive life satisfaction also increases YoGL slightly for all countries simultaneously; however, since the country ranking hardly changes (Figure A.3), the conclusions drawn from the results are virtually unaffected.

Figure A.4 shows the difference in the YoGL when using predicted values of physical limitations rather than observed values of physical limitations for Wave 5, which covered a much smaller group of countries than Wave 7. The results show that when the predicted rather than the observed values are used, the YoGL hardly change, and the country ranking remains exactly the same for both men and women. We thus conclude that our predictions are robust.

\section{Conclusion}

Given that the proportion of the population aged 50+ is increasing in European countries, the well-being of older people is an issue that is gaining in relevance. Our aim in the current paper was to contribute to our understanding of quality of life in older age groups by analysing well-being in the population aged 50+ in 26 European countries. Based on the novel indicator "Years of Good Life" (YoGL), we estimated the remaining years of life that an individual can expect to live in a "good" state. Our results uncovered considerable differences in YoGL at age 50 between regions and genders, with the numbers of YoGL being highest in Northern and Western European countries, and lowest in Central and Eastern European countries. While the absolute numbers of YoGL were found to be quite similar for women and men, women were shown to spend a smaller proportion of their higher remaining lifetime in a good state.

In addition to looking at the overall well-being of older people, we further decomposed the indicator into its four dimensions in order to gain a better understanding of why a given population is losing good years of life. Our results show that in Central and Eastern Europe, the numbers of years spent with positive life satisfaction are particularly low; while in Southern Europe, the loss of YoGL is mainly attributable to low levels of physical and cognitive health. Taking this population heterogeneity into account when measuring human well-being may also 
help policy-makers in formulating sustainable prevention strategies aimed at helping individuals maintain their levels of well-being in old age. Depending on the specific dimensions from which country-specific deficiencies in well-being emerge, policies may seek to increase opportunities for lifelong learning, reduce barriers to social and societal participation in later life, or improve health literacy among older adults. By shedding light on the existing deficiencies in the well-being of older Europeans, and on how these deficiencies differ between countries and between men and women, we hope to inform the development of policies that ultimately aim to improve the quality of life of the elderly in a more holistic way.

Although a range of sensitivity analyses suggest that our results are robust, this study has potential limitations. As our estimates are largely based on survey data, our results are heavily dependent on the selection of participants. For example, highly educated individuals are more likely to participate in surveys, which could, in turn, distort the results through the non-representativeness of the population (Spitzer 2020). Furthermore, our results are built on an indicator that is tailor-made for global analyses, with the thresholds for each dimension designed to reflect the diverse development stages of countries worldwide. While this approach is helpful when making global comparisons, it may lose some of its informative value when the thresholds are applied to a specific set of countries only. For example, given that the World Bank poverty line for upper-middle income countries is US\$5.50, it would appear that virtually no European lives in poverty. Thus, our estimates hardly reflect the relatively high poverty risk that older women in Europe face. Future research may expand our estimates of well-being in the population aged 50+ to a global scale.

\section{Acknowledgements}

The research leading to these results has received funding from the European Research Council (ERC) under the European Union's Horizon 2020 research and innovation programme (grant agreement no 741105). This paper uses data from SHARE Waves 5 and 7 (DOIs: 10.6103/SHARE.w5.700, and 10.6103/SHARE.w7.700). The SHARE data collection has been funded by the European Commission through FP5 (QLK6-CT-2001-00360), FP6 (SHARE-I3: RII-CT-2006-062193, COMPARE: CIT5-CT-2005-028857, SHARELIFE: CIT4CT-2006-028812), FP7 (SHARE-PREP: GA N ${ }^{\circ} 11909$, SHARE-LEAP: GA $\mathrm{N}^{\circ}$ 227822, SHARE M4: GA $\mathrm{N}^{\circ}$ 261982) and Horizon 2020 (SHARE-DEV3: GA $\mathrm{N}^{\circ}$ 676536, SERISS: GA $\mathrm{N}^{\circ}$ 654221) and by DG Employment, Social Affairs \& Inclusion. Additional funding from the German Ministry of Education and Research, the Max Planck Society for the Advancement of Science, the U.S. National Institute on Aging (U01_AG09740-13S2, P01_AG005842, P01_AG08291, P30_AG12815, R21_AG025169, Y1-AG-4553-01, IAG_BSR06-11, OGHA_04-064, HHSN271201300071C) and from various national funding sources is gratefully acknowledged (see www.share-project.org). 


\section{References}

Angelini, V., D. Cavapozzi, L. Corazzini and O. Paccagnella 2012. Age, health and life satisfaction among older Europeans. Social Indicators Research 105(2): 293-308. https://doi.org/10.1007/s11205-011-9882-x

Bergmann, M., A. Scherpenzeel and A. Börsch-Supan (eds) 2019. SHARE Wave 7 Methodology: Panel Innovations and Life Histories. Munich: MEA, Max Planck Institute for Social Law and Social Policy.

Börsch-Supan, A. 2019a. Survey of Health, Ageing and Retirement in Europe (SHARE) Wave 5. Release version: 7.0.0. SHARE-ERIC. Data set. Retrieved from 10.6103/SHARE.w5.700

Börsch-Supan, A. 2019b. Survey of Health, Ageing and Retirement in Europe (SHARE) Wave 7. Release version: 7.0.0. SHARE-ERIC. Data set. Retrieved from 10.6103/SHARE.w7.700

Börsch-Supan, A., M. Brandt, C. Hunkler, T. Kneip, J. Korbmacher, F. Malter, ... S. Zuber 2013. Data resource profile: The Survey of Health, Ageing and Retirement in Europe (SHARE). International Journal of Epidemiology 42(4): 992-1001.

Desai, M., A. Sen and J. Boltvinik 1992. Social Progress Index: A Proposal. Bogotá: United Nations Development Programme.

di Lego, V., P. Di Giulio and M. Luy 2020. The male-female health-mortality paradox. Encyclopedia of Geronotology and Population Aging, eds D. Gu and M. Dupre. Springer.

Dingemans, E. and K. Henkens 2018. Life satisfaction of working retirees in Europe. Netspar Academic Series, (DP 06/2018-032).

Djankov, S., E. Nikolova and J. Zilinsky 2016. The happiness gap in Eastern Europe. Journal of Comparative Economics 44(1): 108-124. https://doi.org/10.1016/j.jce.2015.10.006

Eurostat 2020a. General government expenditure by function (COFOG). Retrieved April 8, 2020, from https://appsso.eurostat.ec.europa.eu/nui/show.do?dataset=gov_10a_ exp\&lang=en

Eurostat 2020b. Life table. Retrieved April 7, 2020, from https://appsso.eurostat.ec.europa. eu/nui/show.do?dataset=demo_mlifetable\&lang=en

Eurostat 2020c. People at risk of poverty or social exclusion. Retrieved April 27, 2020, from https://ec.europa.eu/eurostat/databrowser/view/t2020_50/default/table?lang=en

Ferreira, F. and C. Sánchez-Páramo 2017. A richer array of international poverty lines. Retrieved April 9, 2020, from https://blogs.worldbank.org/developmenttalk/richer-arrayinternational-poverty-lines

Grodstein, F., J. Chen, R. S. Wilson and J. E. Manson 2001. Type 2 diabetes and cognitive function in community-dwelling elderly women. Diabetes Care 24(6): 1060-1065.

Guriev, S. and E. Zhuravskaya 2009. (Un)Happiness in Transition. Journal of Economic Perspectives Figure 23(2): 143-168. https://doi.org/10.1257/jep.23.2.143

Heijink, R., P. Van Baal, M. Oppe, X. Koolman and G. Westert 2011. Decomposing cross-country differences in quality adjusted life expectancy: The impact of value sets. Population Health Metrics 9. https://doi.org/10.1186/1478-7954-9-17

Horley, J. and J. J. Lavery 1995. Subjective well-being and age. Social Indicators Research 34: 275-282. https://doi.org/10.1007/BF01079200 
Jagger, C., C. Gillies, F. Moscone, E. Cambois, H. Van Oyen, W. Nusselder and J. M. Robine 2008. Inequalities in healthy life years in the 25 countries of the European Union in 2005: A cross-national meta-regression analysis. The Lancet 372(9656): 2124-2131. https://doi.org/10.1016/S0140-6736(08)61594-9

Kutubaeva, R. Z. 2019. Analysis of life satisfaction of the elderly population on the example of Sweden, Austria and Germany. Population and Economics 3(3): 102-116. https://doi. org/10.3897/popecon.3.e47192

Lelkes, O. 2008. Happiness across the life cycle: Exploring age-specific preferences. European Centre Policiy Brief (2).

Lutz, W., E. Striessnig, A. Dimitrova, S. Ghislandi, A. Lijadi, C. Reiter, S. Spitzer and D. Yildiz 2021. Years of Good Life (YoGL) is a wellbeing indicator designed to serve research on sustainability. Proceedings of the National Academy of Sciences of the United States of America, 118(12): e1907351118. https://doi.org/10.1073/pnas.1907351118

Luy, M. and Y. Minagawa 2014. Gender gaps - life expectancy and proportion of life in poor health. Health Reports 25(12): 12-19.

Malter, F. and A. Börsch-Supan (eds) 2015. SHARE Wave 5: Innovations $\mathcal{F}$ Methodology. Munich: MEA, Max Planck Institute for Social Law and Social Policy.

Matson, P., W. C. Clark and K. Andersson 2016. Pursuing sustainability: A guide to the science and practice. Princeton University Press.

Murray, C. J. and A. D. Lopez 1994. Quantifying disability: Data, methods and results. Bulletin of the World Health Organization 72(3): 481-494.

Netuveli, G. and D. Blane 2008. Quality of life in older ages. British Medical Bulletin 85(1): 113-126. https://doi.org/10.1093/bmb/ldn003

OECD 2008. Growing unequal? Income distribution and poverty in OECD countries. Retrieved from https://read.oecd-ilibrary.org/social-issues-migration-health/growingunequal_9789264044197-en\#page1

OECD 2011. Divided we stand: Why inequality keeps rising. Paris: OECD Publishing. https://doi.org/10.1787/9789264119536-en

Pongiglione, B., B. L. De Stavola and G. B. Ploubidis 2015. A systematic literature review of studies analyzing inequalities in health expectancy among the older population. PLoS ONE 10(6): 1-21. https://doi.org/10.1371/journal.pone.0130747

Purser, J. L., G. G. Fillenbaum, C. F. Pieper and R. B. Wallace 2005. Mild cognitive impairment and 10-year trajectories of disability in the Iowa established populations for epidemiologic studies of the elderly cohort. Journal of the American Geriatrics Society 53(11): 1966-1972.

Reiter, C. and W. Lutz 2020. Survival and years of good life in Finland in the very long run. Finnish Yearbook of Population Research 54: 1-27. https://doi.org/10.23979/fypr.87148

Robine, J.-M. 2006. Summarizing health status. Oxford Handbook of Public Health Practice (2nd ed.), eds D. Pencheon, C. Guest, D. Melzer and J. Gray. Oxford: Oxford University Press.

Sanfey, P. and Teksoz, U. 2007. Does transition make you happy? Economics of Transition 15(4): 707-731. https://doi.org/10.1111/j.1468-0351.2007.00309.x 
Spitzer, S. 2020. Biases in health expectancies due to educational differences in survey participation of older Europeans: It's worth weighting for. European Journal of Health Economics 21: 573-605. https://doi.org/10.1007/s10198-019-01152-0

Spitzer, S. and D. Weber 2019. Reporting biases in self-assessed physical and cognitive health status of older Europeans. PLoS ONE 14(10): e0223526. https://doi.org/10.1371/ journal.pone.0223526

Steptoe, A., A. Deaton and A. A. Stone 2015. Subjective wellbeing, health, and ageing. The Lancet 385: 640-648. https://doi.org/10.1016/S0140-6736(13)61489-0

Sullivan, D. F. 1971. A single index of mortality and morbidity. HSMHA Health Reports 86(4): 347-354.

UN System Chief Executives Board for Coordination 2017. Leaving no one behind: Equality and Non-discrimination at the Heart of Sustainable Development. New York. Retrieved August 10, 2020, from https://www.unsceb.org/CEBPublicFiles/CEB\%20equality\% 20framework-A4-web-rev3.pdf

United Nations 2019. World population prospects 2019. Retrieved May 13, 2020, from https://population.un.org/wpp/

United Nations Development Programme 2019. Human Development Report 2019: Beyond income, beyond averages, beyond today: Inequalities in human development in the 21 st century.

Wittgenstein Centre for Demography and Global Human Capital 2018. Wittgenstein Centre Data Explorer Version 2.0 (Beta). Retrieved February 22, 2020, from http: //www.wittgensteincentre.org/dataexplorer

World Health Organization 2018. Ageing and health. Retrieved April 28, 2020, from https: //www.who.int/news-room/fact-sheets/detail/ageing-and-health

Zeckhauser, R. and D. Shepard 1976. Where now for saving lives? Law and Contemporary Problems 40(4): 5-45. 


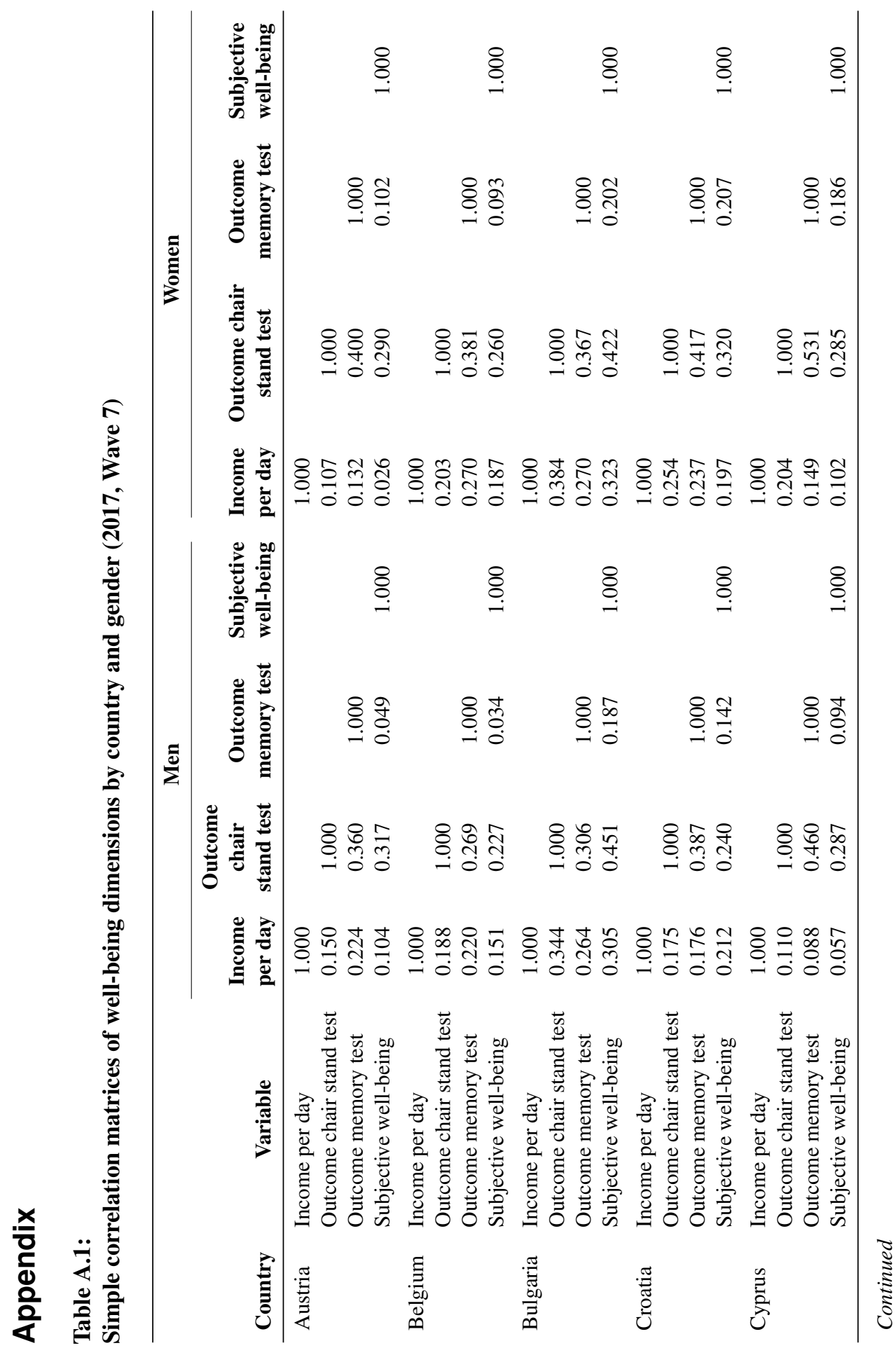




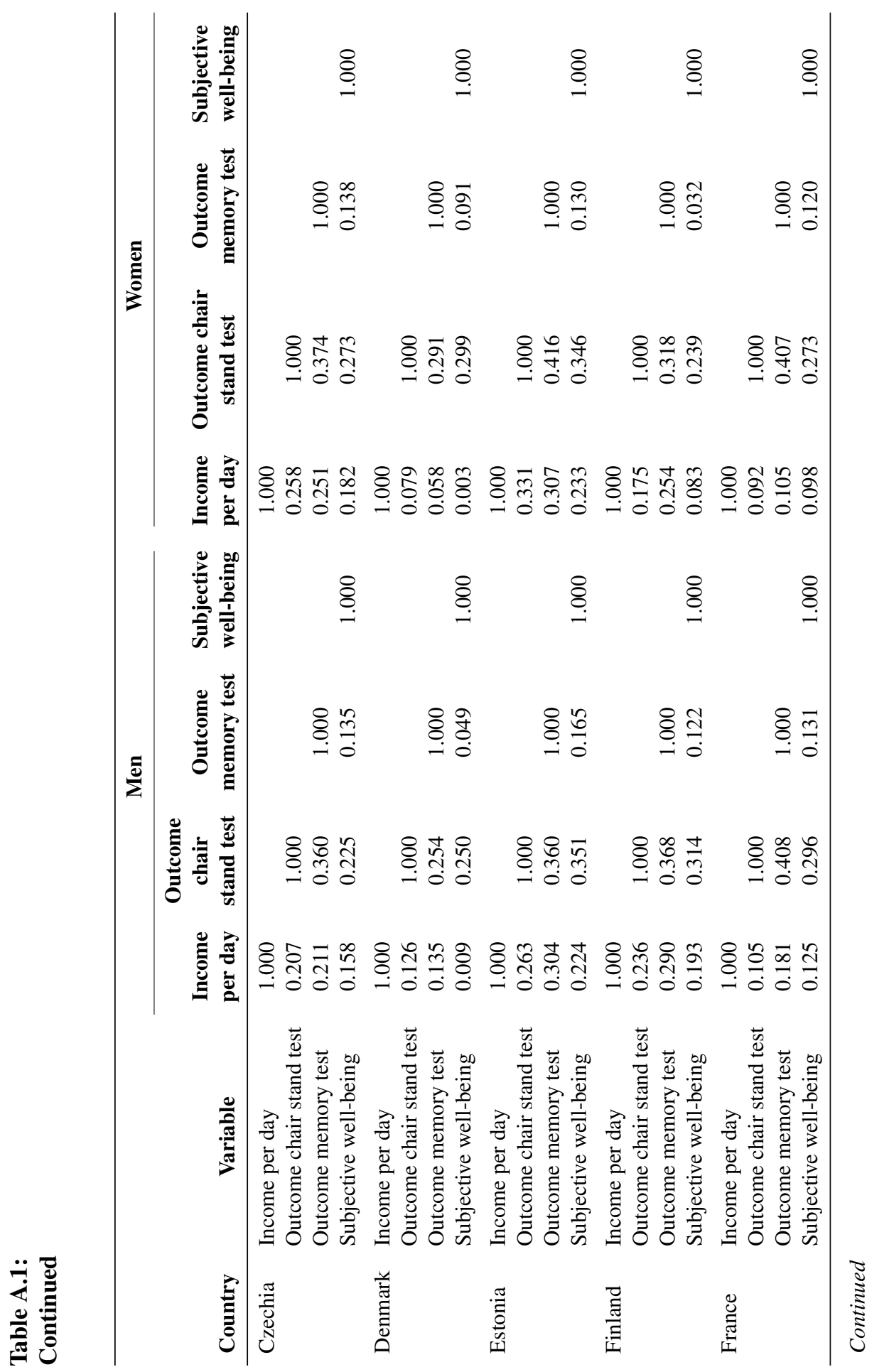




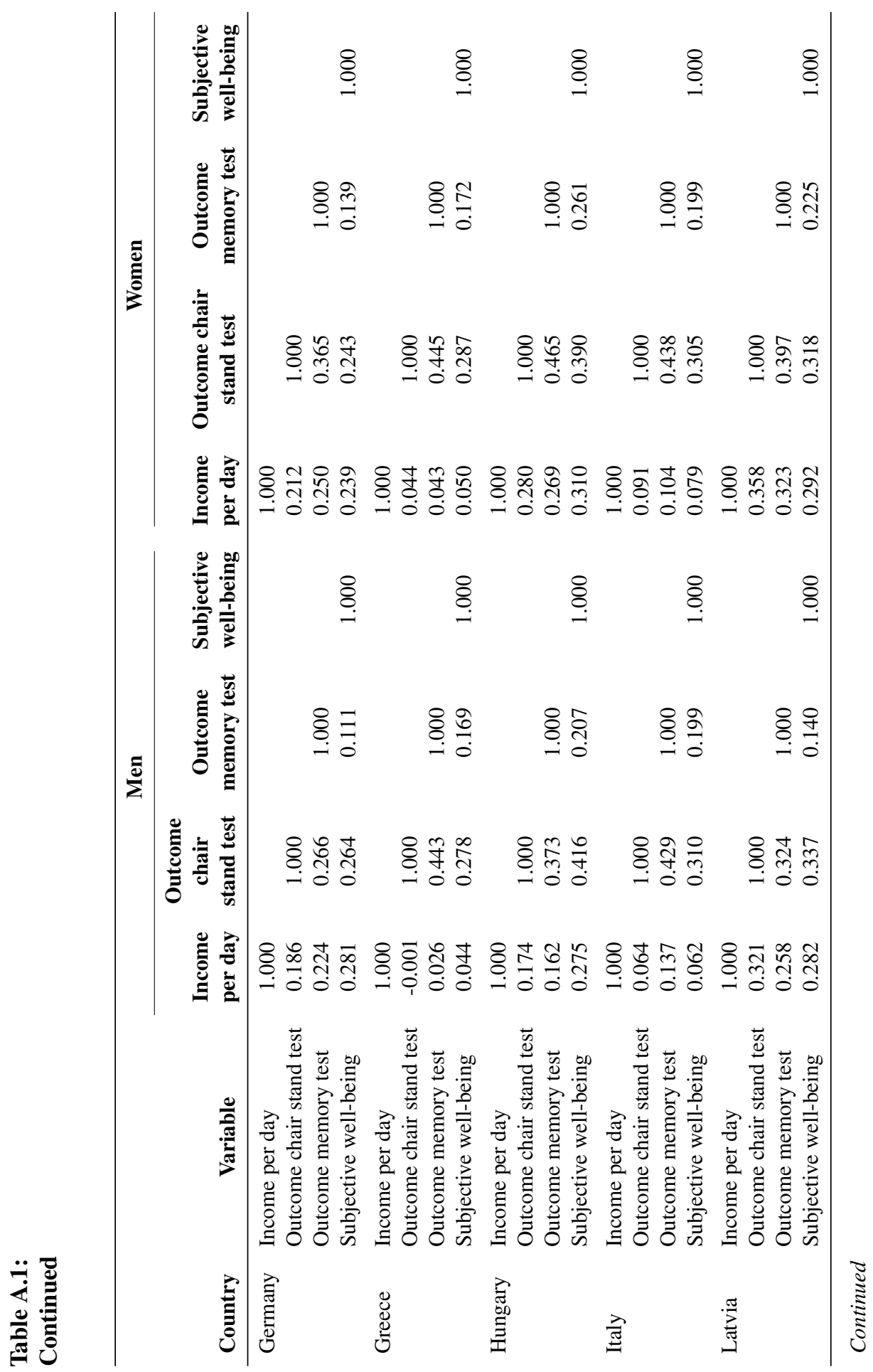




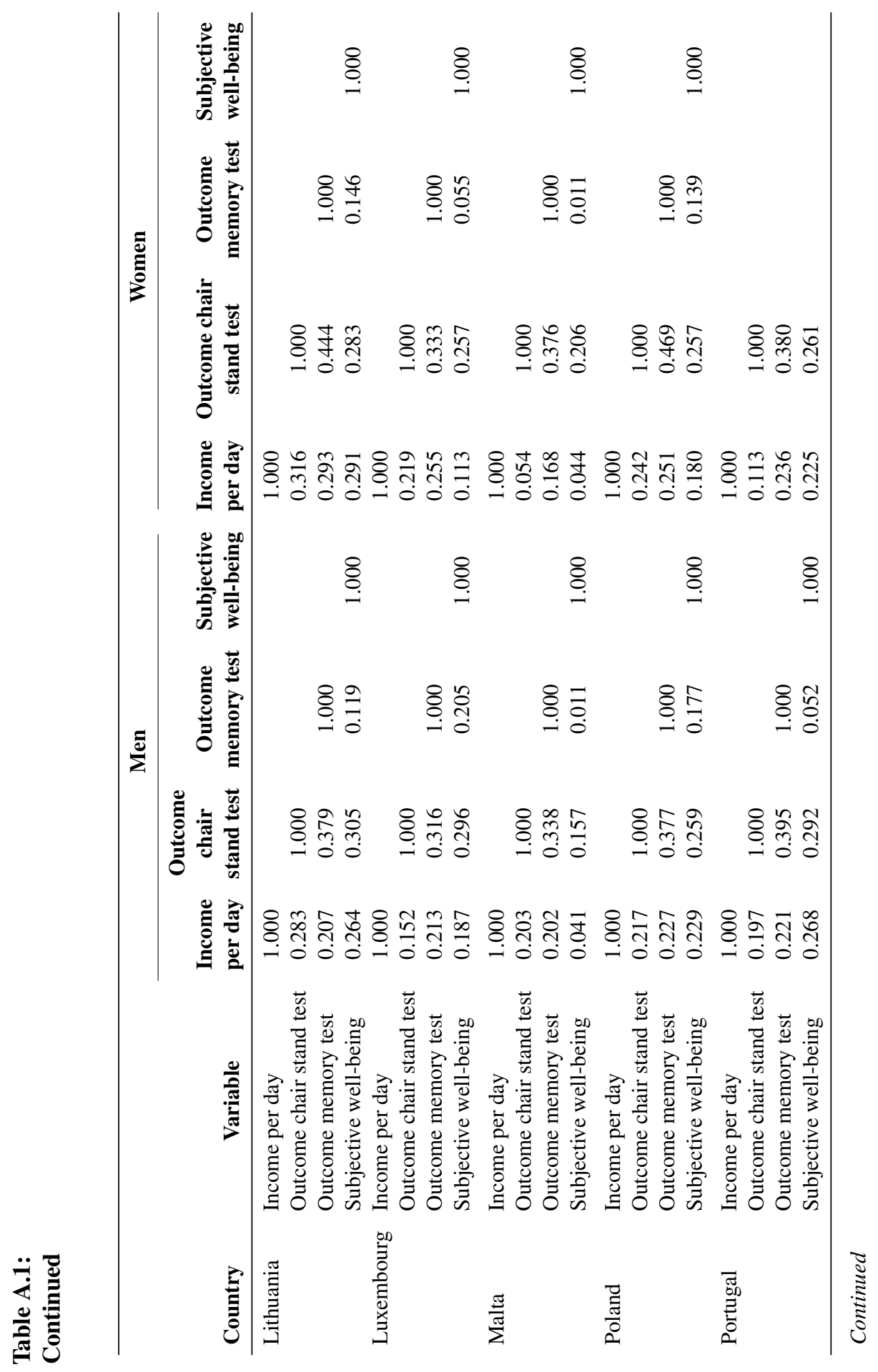




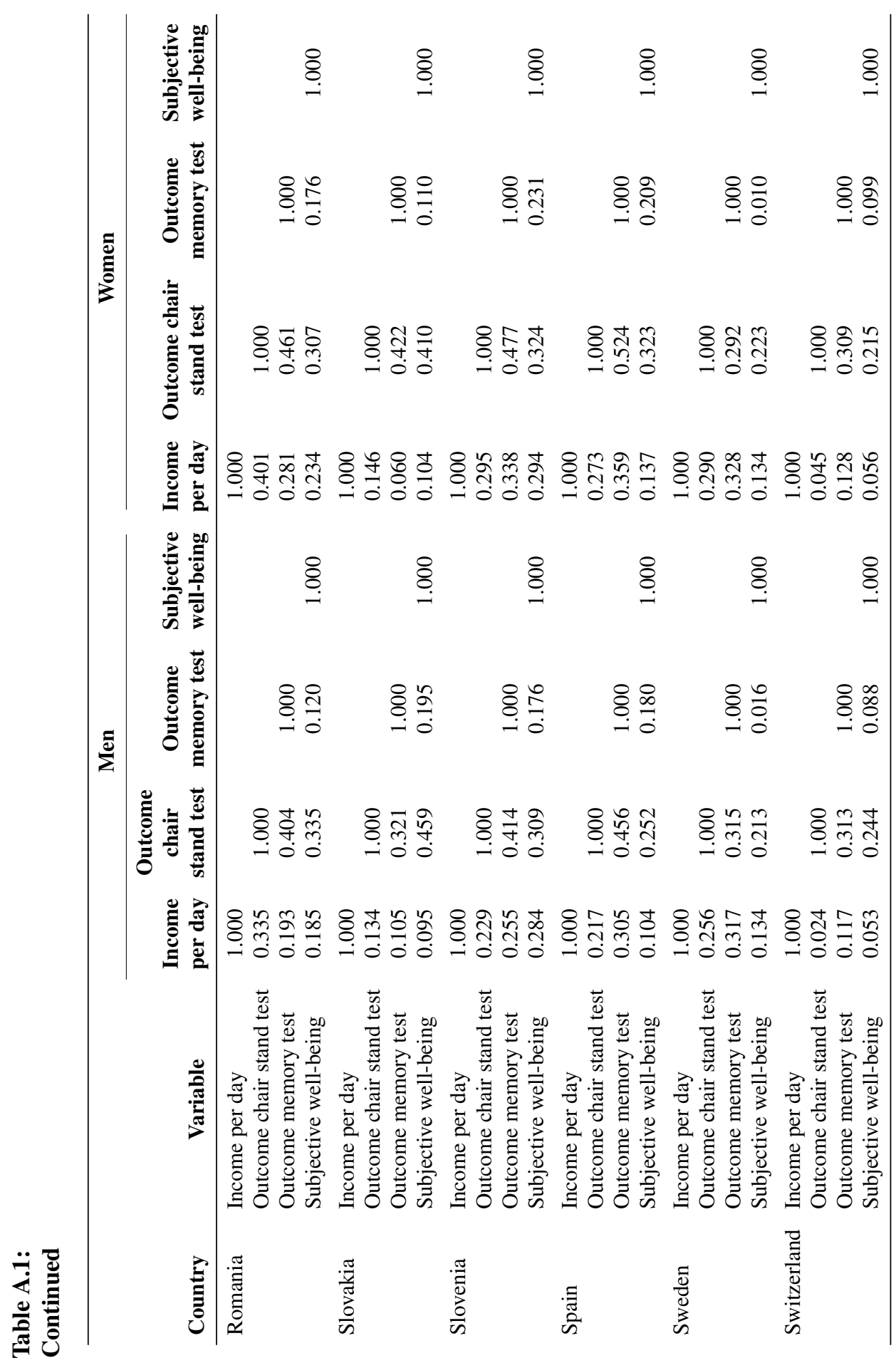


Table A.2:

Summary statistics for the predictor variables (2013, Wave 5)

\begin{tabular}{|c|c|c|c|c|c|}
\hline & $N$ & Mean & SD & Min. & Max. \\
\hline Out of poverty $(1=$ yes $)$ & 58,947 & 1.00 & 0.014 & 0 & 1 \\
\hline Cognitively able $(1=$ yes $)$ & 58,823 & 0.84 & 0.362 & 0 & 1 \\
\hline Satisfied with life ( $1=$ yes) & 59,377 & 0.85 & 0.353 & 0 & 1 \\
\hline Gender $(1$ = woman $)$ & 59,377 & 0.54 & 0.499 & 0 & 1 \\
\hline Age (in number of years) & 59,377 & 66.11 & 10.645 & 51 & 104 \\
\hline Low education $(1=$ yes $)$ & 58,504 & 0.42 & 0.493 & 0 & 1 \\
\hline Medium education $(1=$ yes $)$ & 58,504 & 0.37 & 0.484 & 0 & 1 \\
\hline High education $(1=$ yes $)$ & 58,504 & 0.21 & 0.406 & 0 & 1 \\
\hline Retired $(1=$ yes $)$ & 58,874 & 0.51 & 0.500 & 0 & 1 \\
\hline Married (1 = yes) & 57,447 & 0.66 & 0.474 & 0 & 1 \\
\hline Partner in same household $(1=$ yes $)$ & 59,377 & 0.66 & 0.473 & 0 & 1 \\
\hline Household size & 59,377 & 2.10 & 1.001 & 1 & 11 \\
\hline Wealth quintile & 59,377 & 2.94 & 1.431 & 1 & 5 \\
\hline Subjective ability chair stand $(1=$ able $)$ & 59,362 & 0.82 & 0.383 & 0 & 1 \\
\hline Number of chronic diseases & 59,280 & 1.21 & 1.272 & 0 & 10 \\
\hline Number of instrumental activity limitations & 59,359 & 0.50 & 1.528 & 0 & 13 \\
\hline Heart attack $(1=$ yes $)$ & 59,280 & 0.11 & 0.309 & 0 & 1 \\
\hline Diabetes $(1=$ yes $)$ & 59,280 & 0.12 & 0.329 & 0 & 1 \\
\hline Lung disease $(1=$ yes $)$ & 59,280 & 0.06 & 0.246 & 0 & 1 \\
\hline Cancer $(1=$ yes $)$ & 59,280 & 0.06 & 0.235 & 0 & 1 \\
\hline Stroke $(1=$ yes $)$ & 59,280 & 0.03 & 0.179 & 0 & 1 \\
\hline Parkinson $(1=$ yes $)$ & 59,280 & 0.01 & 0.082 & 0 & 1 \\
\hline Alzheimer $(1=$ yes $)$ & 59,280 & 0.01 & 0.077 & 0 & 1 \\
\hline Walking 100 metres $(1=$ able $)$ & 59,362 & 0.10 & 0.305 & 0 & 1 \\
\hline Sitting for two hours $(1=$ able $)$ & 59,362 & 0.10 & 0.303 & 0 & 1 \\
\hline Climbing stairs $(1=$ able $)$ & 59,362 & 0.12 & 0.320 & 0 & 1 \\
\hline Stooping, kneeling or crouching $(1=$ able $)$ & 59,362 & 0.30 & 0.458 & 0 & 1 \\
\hline Pulling or pushing large objects $(1=$ able $)$ & 59,362 & 0.13 & 0.333 & 0 & 1 \\
\hline Lifting weights over 5 kilos $(1=$ able $)$ & 59,362 & 0.20 & 0.399 & 0 & 1 \\
\hline Walking across a room $(1=$ able $)$ & 59,359 & 0.02 & 0.134 & 0 & 1 \\
\hline Getting in or out of bed $(1=$ able $)$ & 59,359 & 0.03 & 0.171 & 0 & 1 \\
\hline $\begin{array}{l}\text { Doing work around house or } \\
\text { garden }(1=\text { able })\end{array}$ & 59,359 & 0.10 & 0.300 & 0 & 1 \\
\hline Region Northern Europe ( 1 = yes) & 59,377 & 0.05 & 0.209 & 0 & 1 \\
\hline Region Southern Europe $(1=$ yes $)$ & 59,377 & 0.32 & 0.465 & 0 & 1 \\
\hline $\begin{array}{l}\text { Region Central and Eastern Europe } \\
\quad(1=\text { yes })\end{array}$ & 59,377 & 0.04 & 0.200 & 0 & 1 \\
\hline Region Western Europe $(1=$ yes $)$ & 59,377 & 0.60 & 0.491 & 0 & 1 \\
\hline
\end{tabular}

Note: Cross-sectional individual SHARE survey weights are applied; region categories: Northern Europe (Sweden, Denmark, Finland), Southern Europe (Spain, Italy, Greece, Portugal, Cyprus, Malta), Central and Eastern Europe (Czechia, Poland, Hungary, Slovenia, Estonia, Croatia, Lithuania, Bulgaria, Latvia, Romania, Slovakia), Western Europe (Austria, Germany, Netherlands, France, Switzerland, Belgium, Ireland, Luxembourg) 
Table A.3:

Output table prediction model for chair stand (2013, Wave 5)

\begin{tabular}{|c|c|c|}
\hline & Coef. & SE \\
\hline Self-reported ability chair stand $($ ref $=$ unable $)$ & $0.539^{* * *}$ & $(0.037)$ \\
\hline Women & 0.001 & $(0.029)$ \\
\hline Age $55-59($ ref $=$ age $50-54)$ & -0.098 & $(0.065)$ \\
\hline Age $60-64($ ref $=$ age $50-54)$ & -0.053 & $(0.067)$ \\
\hline Age $65-69($ ref $=$ age $50-54)$ & $-0.200^{* *}$ & $(0.072)$ \\
\hline Age $70-74($ ref $=$ age $50-54)$ & $-0.228^{* *}$ & $(0.075)$ \\
\hline Age $75-79($ ref $=$ age $50-54)$ & $-0.405^{* * *}$ & $(0.076)$ \\
\hline Age $80-84($ ref $=$ age $50-54)$ & $-0.704^{* * *}$ & $(0.080)$ \\
\hline Age $85-89($ ref $=$ age $50-54)$ & $-0.992^{* * *}$ & $(0.092)$ \\
\hline Age $90+($ ref $=$ age $50-54)$ & $-1.253^{* * *}$ & $(0.136)$ \\
\hline Medium education ( $\mathrm{ref}=$ low education $)$ & $0.074^{*}$ & $(0.034)$ \\
\hline High education (ref $=$ low education) & $0.190^{* * *}$ & $(0.044)$ \\
\hline Retired $($ ref $=$ no $)$ & 0.006 & $(0.040)$ \\
\hline Married $($ ref $=$ no) & $0.117^{*}$ & $(0.059)$ \\
\hline $2^{\text {nd }}$ wealth quintile (ref $=1^{\text {st }}$ wealth quintile) & $0.174^{* * *}$ & $(0.043)$ \\
\hline $3^{\text {rd }}$ wealth quintile (ref $=1^{\text {st }}$ wealth quintile) & $0.192^{* * *}$ & $(0.045)$ \\
\hline $4^{\text {th }}$ wealth quintile (ref $=1^{\text {st }}$ wealth quintile) & $0.284^{* * *}$ & $(0.047)$ \\
\hline $5^{\text {th }}$ wealth quintile (ref $=1^{\text {st }}$ wealth quintile) & $0.358^{* * *}$ & $(0.049)$ \\
\hline Number of chronic diseases & 0.017 & $(0.016)$ \\
\hline Number of instrumental activity limitations & $-0.060^{* *}$ & $(0.019)$ \\
\hline Heart attack $($ ref $=$ no $)$ & -0.039 & $(0.046)$ \\
\hline Diabetes $($ ref $=$ no $)$ & $-0.268^{* * *}$ & $(0.044)$ \\
\hline Lung disease $(\mathrm{ref}=$ no $)$ & -0.081 & $(0.056)$ \\
\hline Cancer $($ ref $=$ no $)$ & $-0.179^{* *}$ & $(0.057)$ \\
\hline Alzheimer $($ ref $=$ no $)$ & 0.271 & $(0.148)$ \\
\hline Health expenditure in mio. Euro (country-level) & -0.006 & $(0.011)$ \\
\hline Southern Europe (ref = Northern) & $-0.825^{* * *}$ & $(0.062)$ \\
\hline Central and Eastern Europe (ref $=$ Northern) & $-0.767^{* * *}$ & $(0.058)$ \\
\hline Western Europe (ref = Northern) & $-0.234^{* * *}$ & $(0.052)$ \\
\hline Lives with partner $($ ref $=$ no $)$ & -0.040 & $(0.064)$ \\
\hline Household size & 0.031 & $(0.021)$ \\
\hline Stroke $($ ref $=$ no $)$ & $-0.284^{* * *}$ & $(0.069)$ \\
\hline Parkinson $($ ref $=$ no $)$ & $-0.437^{* *}$ & $(0.137)$ \\
\hline Walking 100 metres $($ ref $=$ no) & $-0.638^{* * *}$ & $(0.045)$ \\
\hline Sitting for two hours $($ ref $=$ no) & 0.001 & $(0.044)$ \\
\hline
\end{tabular}

Continued 
Table A.3:

Continued

\begin{tabular}{lcc}
\hline & Coef. & SE \\
\hline Climbing stairs (ref = no) & $-0.652^{* * *}$ & $(0.042)$ \\
Stooping, kneeling or crouching (ref = no) & $-0.589^{* * *}$ & $(0.034)$ \\
Pulling or pushing large objects (ref = no) & $-0.376^{* * *}$ & $(0.042)$ \\
Lifting weights over 5 kilos (ref = no) & $-0.282^{* * *}$ & $(0.039)$ \\
Walking across a room (ref = no) & $-0.569^{* * *}$ & $(0.132)$ \\
Getting in or out of bed (ref = no) & -0.040 & $(0.083)$ \\
Doing work around house or garden (ref = no) & $-0.438^{* * *}$ & $(0.056)$ \\
Cognitively able (ref = no) & $0.571^{* * *}$ & $(0.038)$ \\
Out of poverty (ref = no) & $2.921^{*}$ & $(1.279)$ \\
Satisfied with life (ref = no) & $0.273^{* * *}$ & $(0.037)$ \\
Constant & -1.160 & $(1.287)$ \\
Pseudo R & 0.271 & \\
$N$ & 56,082 & \\
SE & clustered & \\
\hline
\end{tabular}

Note: Dependent variable $=$ tested ability chair stand. ${ }^{*} p<0.05,{ }^{* *} p<0.01,{ }^{* * *} p<0.001$.

\section{Figure A.1:}

Comparison of observed and predicted shares without physical limitations in the population aged $50+(2013$, Wave 5)

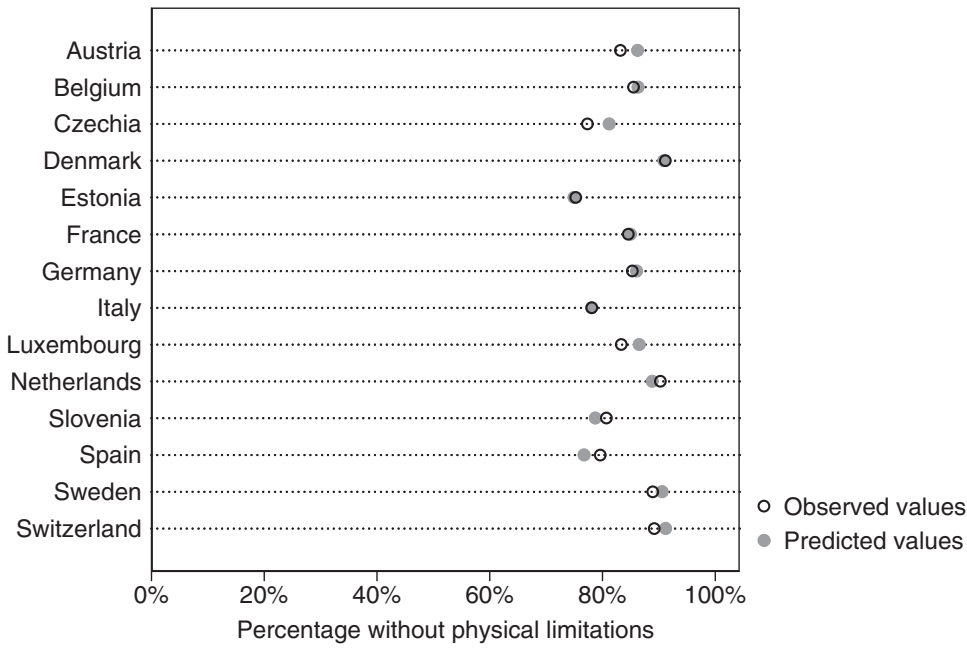

Note: Cross-sectional individual SHARE survey weights are applied. 


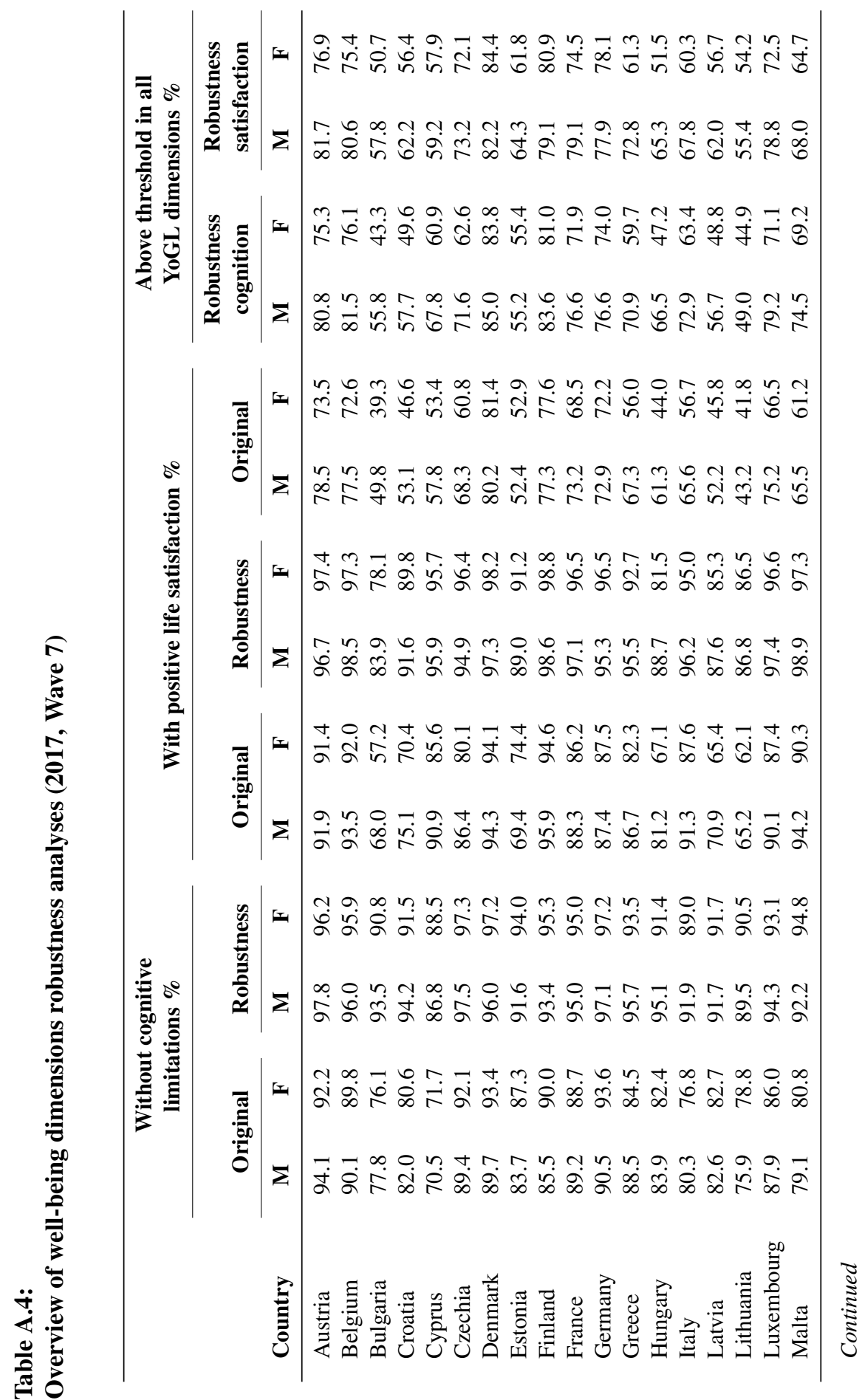




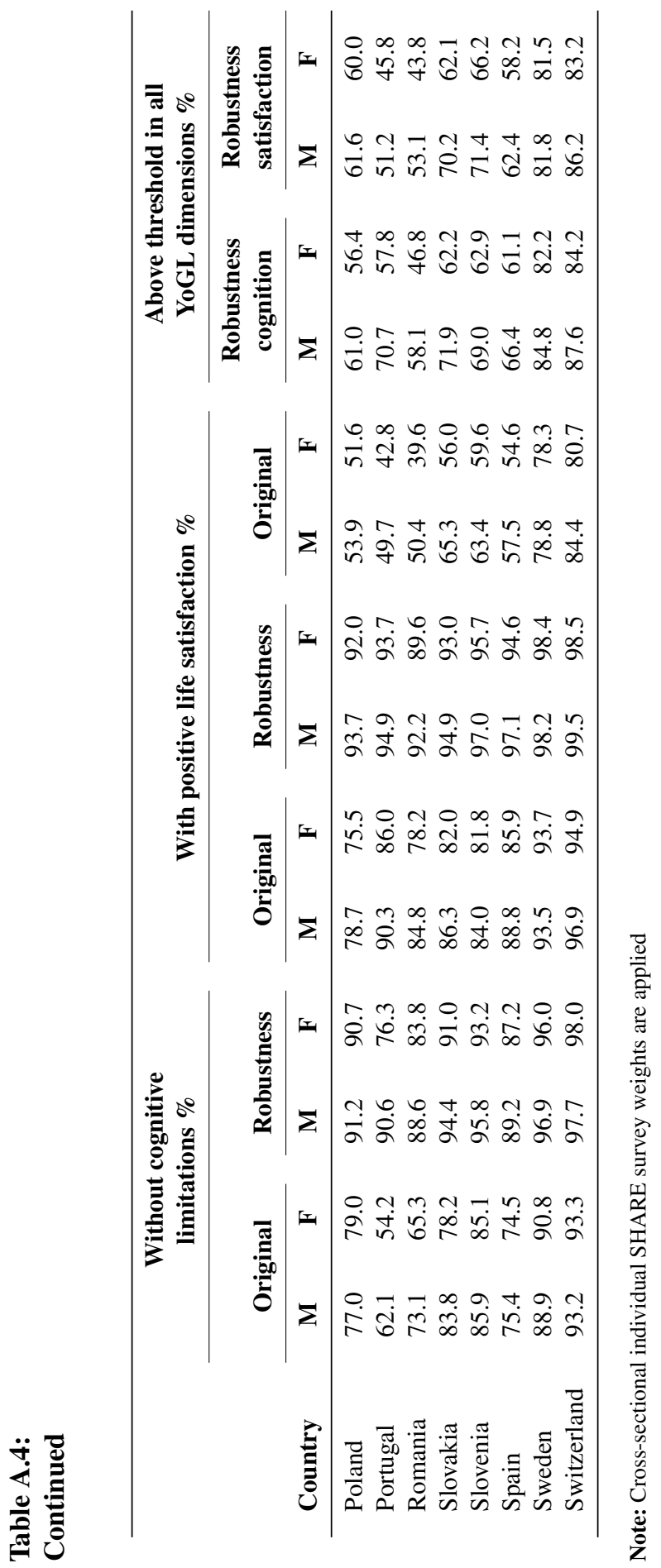


Figure A.2:

Remaining Years of Good Life at age 50 by country and gender - robustness analysis applying a different threshold for cognitive limitations (2017, Wave 7)

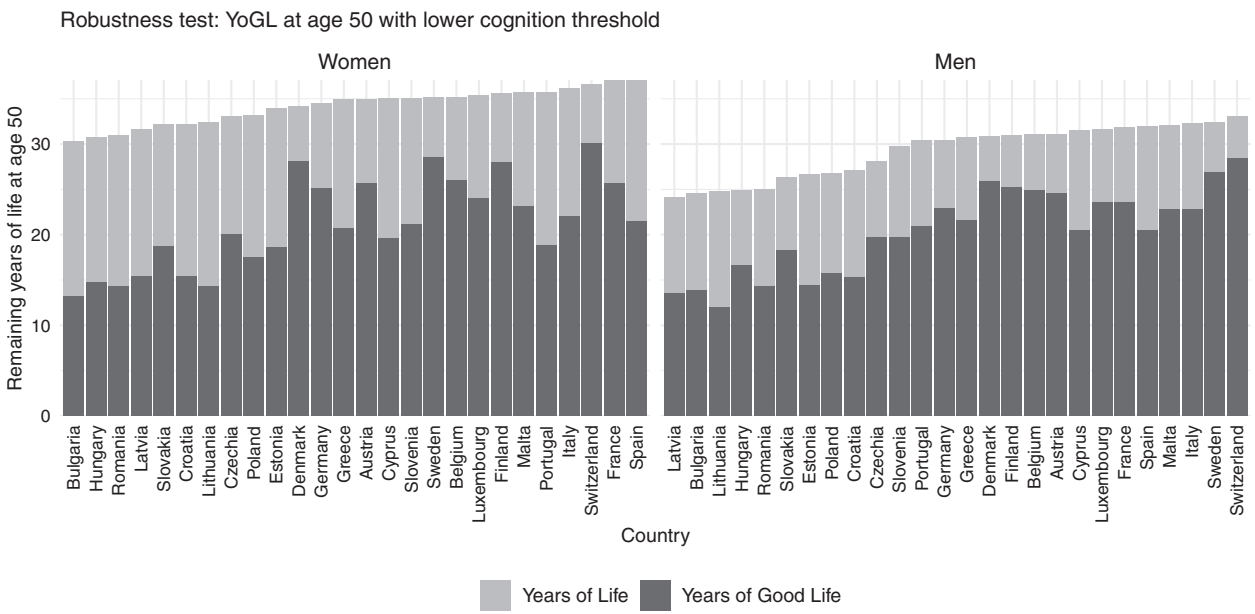

Note: Cross-sectional individual SHARE survey weights are applied.

Figure A.3:

Remaining Years of Good Life at age 50 by country and gender - robustness analysis applying a different threshold for positive life satisfaction (2017, Wave 7)

Robustness test: YoGL at age 50 with lower life satisfaction threshold

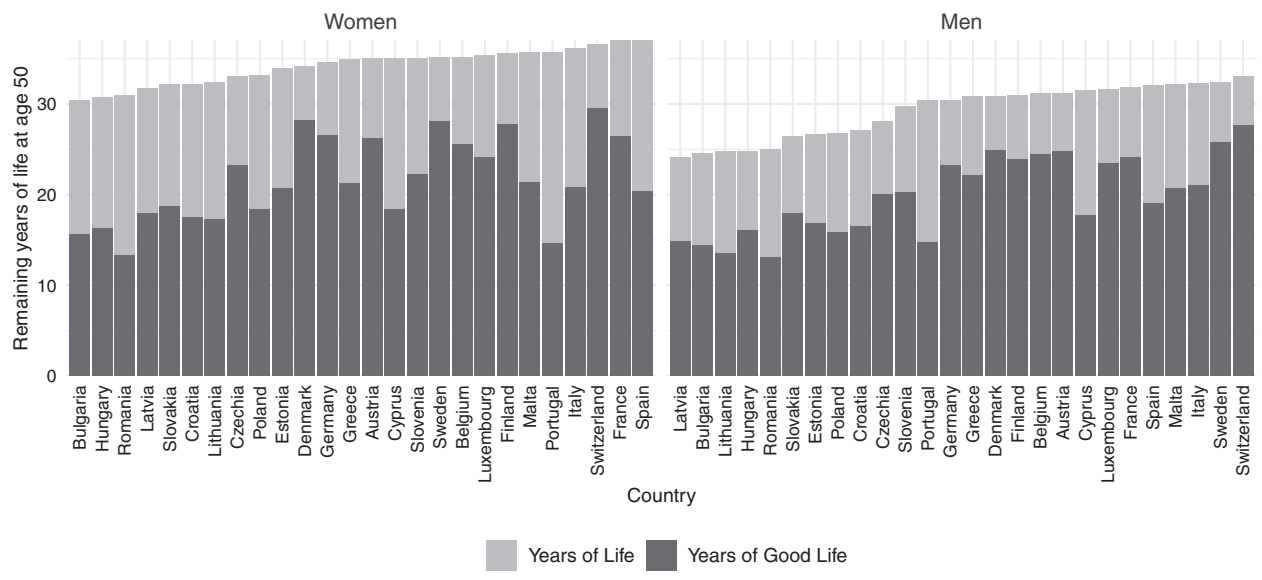

Note: Cross-sectional individual SHARE survey weights are applied. 
Figure A.4:

Remaining Years of Good Life at age 50 by country and gender - robustness analysis comparing results based on observed and predicted physical limitations (2013, Wave 5)

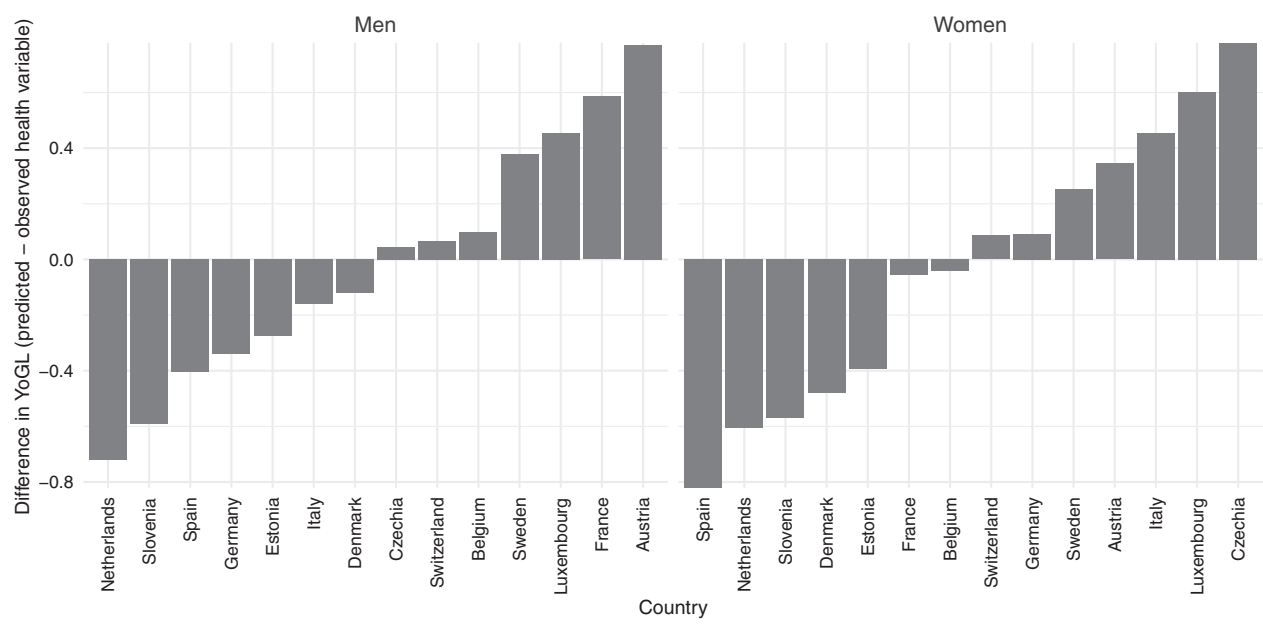

Note: Cross-sectional individual SHARE survey weights are applied.

Open Access This article is published under the terms of the Creative Commons Attribution 4.0 International License (https://creativecommons.org/licenses/by/4.0/) that allows the sharing, use and adaptation in any medium, provided that the user gives appropriate credit, provides a link to the license, and indicates if changes were made. 